\title{
Below Replacement-Level Fertility in Conditions of Slow Social and Economic Development: A Review of the Evidence From South India
}

\author{
MINNA SÄÄVÄLÄ, Ph.D., Senior Researcher \\ Population Research Institute, Väestöliitto, Helsinki, Finland
}

\begin{abstract}
Demographic interest in the explanations of the first fertility transition has receded considerably during the last decade. Despite the empirical evidence of global convergence in fertility, there is still no consensus on the factors which explain the swiftness of the change in some contexts and its deceleration in some others. From the policy perspective, it remains pivotal to locate the factors that affect the momentum of fertility transition. In this essay the fast decline to below replacement-level period Total Fertility Rate in South India will be examined as an example of fertility transition despite slow social and/or economic development. The analysis is based on a literature review of empirical studies on the determinants of regional fertility differentials in India. Some southern states, most particularly Andhra Pradesh, manifest below replacement-level fertility (TFR 1.79) despite low average age at marriage even in Indian terms, the resilience of women's universal marriage, and heavy reliance on a terminal family planning method, female sterilization. The case of Andhra Pradesh shows that below-replacement level fertility can occur despite slow social development, widespread poverty and gender asymmetries. Geographical and social diffusion effects are partly responsible of the speed of the decline, although they are difficult to measure or test in the level of fertility decision-making.
\end{abstract}

Keywords: Fertility transition, poverty, gender, diffusion, Andhra Pradesh, India

\section{Background}

Demographic interest in the first fertility transition in Third World countries has receded considerably during the last decade in the face of the inconsistent empirical evidence of the decontextualized determinants of fertility decline and the nearly universal emergence of fertility transition (Dyson 2002; Bongaarts 2008; McNicoll 2009; Lesthaeghe 2010). Even if the explanation of the global fertility transition is not agreed upon, it is nevertheless no longer much debated or theorized (McNicoll 2009, 780). ${ }^{1}$ Its analytical treatment nowadays relies more on "qualitative argument" (ibid.) than on elaborate statistical modeling.

1 But see Nauck (2007) on new empirical developments in the value of children -approach. 
The first demographic transition has gained momentum everywhere apart from a number of Sub-Saharan African countries. The concerns related to global population growth are nevertheless still quite acute, as 39 countries (all in Africa) are still having Total Fertility Rates (TFR) above four, totaling to 815 million people, and fertility decline has been slow in some countries, most importantly for the global population growth, in South Asia. For example, the fertility levels in the populous northern plains of India remain quite high, between 3.7 and 4 (National Family Health Survey NFHS 2005-6, International Institute of Population Sciences IIPS 2007; see Figure 1 below).

Global convergence in fertility is commonly considered as a universal, unidirectional process without an alternative, differing only in the speed of the process (Dorius 2008; Dyson 2002; but see Myrskyla, Kohler and Billari 2009). Even if fertility will most probably sooner or later decline everywhere, the global population growth makes it imperative to identify factors that might accelerate or decelerate the process. The speed of fertility decline has stalled in a number of Sub-Saharan African countries, shedding some doubts on the universality of the models of fertility transition (Bongaarts 2008; Doskoch 2008; Moultrie et al. 2008). On the other hand we have some other areas where the speed in which TFR has declined shows that the riddle of the first fertility transition still deserves attention. Most remarkable examples are Iran that witnessed a post-war decline from TFR of 5.3 to 2.0 within 12 years (Efrani and McQuillan 2008) and Mongolia from 7.2 to 3 within 20 years (Gereltuya 2008).

The factors that usually go hand in hand with fertility decline globally are well known, despite regional idiosyncrasies: falling child mortality, resource constraints, new economic opportunities, exposure to new ways of life and more equitable gender relations, and improved means of birth control (McNicoll 2009). Rapid economic growth has everywhere initiated fertility decline-sooner or later-as a consequence; the negative association of fertility with economic and social development has therefore become one of the most solidly established and generally accepted empirical regularities in the social sciences (Myrskyla et al. 2009). What remains of specific interest is that fertility has declined to replacement-level and even below in some Third World contexts where no fast socio-economic development, industrialization or urbanization has taken place. Southern India is a typical example of such a poverty-plagued context where decline has not stopped at replacement level but continued, even to North European levels of TFR 1.79 at its lowest in the state of Andhra Pradesh in 2005-6 (IIPS 2007).

\section{Aim, data and methods}

This article examines regional fertility differentials in India in order to specify if and how socio-economic development and fertility decline to below-replacement level are inter-related. 
The data derives from a literature review of empirical studies of fertility differentials and fertility transition in India. The search was initially limited to relevant peerreviewed articles published since the year 2000, and later this was supplemented with some particularly relevant earlier empirical analyses. A search with the key words 'India' and 'fertility' in Popline identified 199 peer-reviewed references, and in CSA Sociological Abstracts, 345 articles. Irrelevant articles, such as those relating to reproductive health, abortion, mortality, and sex ratio were left out and 44 relevant references were scrutinized more closely. These were supplemented further with a few essential books, most notably a collection edited by Christophe Z. Guilmoto and S. Irudaya Rajan (2005). In addition to quantitative, multivariate analyses, data on qualitative studies are also included when relevant. The ethnographic case study in Andhra Pradesh by the author (Säävälä 1999, 2001, 2006) was used extensively to contextualize quantitative studies.

\section{The Indian population scenario}

India is the second largest national population in the world with estimated 1.2 billion inhabitants in 2010 (United Nations 2010; U S Census Bureau estimate is 1.173 billion). According to the United Nations medium projection, India will surpass China by the year 2030 and will thus become the most populous nation. ${ }^{2}$ The future demographic prospects of India as well as past population history is thus of great interest to the global population question as well as for other developing countries.

In global media, India possesses a double image: on the one hand, a nation of misery and poverty, on the other, an ICT giant with huge economic potential. Despite the handsome growth in the economy (which has continued despite global recession) and high foreign investment in the ICT technology sector, India is still a predominantly rural country where more than half of the population depends on agriculture (IIPS 2007) and two thirds of the population lives in rural areas. The United Nations' World Food Program estimates that nearly half of the world's hungry live in India, and about 20 percent of the population is undernourished (International Food Policy Research Institute IFPRI 2009). The worst performing state, Madhya Pradesh in central India, is at the same level as Chad and Ethiopia in terms of undernourishment and child mortality, while even the best performing state, Punjab, is below the level reached by Vietnam or Honduras (ibid.).

In the Human Development Index (HDI), India ranked 134th among 182 countries in the year 2007 (UNDP 2009). The Human Development Index measures GNP per inhabitant, life expectancy and level of education. On the basis of only GNP per capita India fares better than in Human Development Index overall: India's economic success has thus far failed to translate into social development and equity to the extent

2 According to the projection of the U S Census Bureau, India would surpass China a bit earlier, by 2025. 
we could expect from other Asian developing countries. The most striking feature of Indian poverty is children's undernutrition. In $2002-7$ close to half (44 percent) of the Indian children below the age of five were suffering from underweight-for-age (IFPRI 2009). Beginning from the year 1970, the percentage of undernourished children has gradually decreased by around 1 percent per year (ibid.).

Despite the problems in social and economic development in the country, many Indian states have now entered the last phase of the classical population transition. According to the third National Family Health Survey (NFHS-3) which was carried out in 2005-6, ten states had attained fertility at or below replacement-level, covering 35 percent of the national population. However, still 25 percent of the population lives in areas where TFR is above 3.6. The national TFR stands in 2.7 children in 2005-6 (according to NFHS-3, IIPS 2007). ${ }^{3}$ Dramatic drops in current fertility have been witnessed in some southern states, most notably Andhra Pradesh, where the TFR has declined from 4.6 in 1971 to 1.8 in 2005-6 (IIPS 2007). Among states that have reached below replacement-level, Goa was the first in the mid 1980s, Kerala in 1988, Tamil Nadu in 1993. Lately, below replacement-level has been reached in the economically more developed Punjab and Maharashtra, and in the mountain regions Himachal Pradesh and Sikkim, and in the southern Andhra Pradesh (Matthews et al. 2009; IIPS 2007, see Figure 1 below). As McNay et al. $(2003,38)$ put it, India "now appears to be moving more quickly than the traditional socio-economic correlates of fertility decline are changing".

Some regional differences in fertility were visible already in the first estimates on birth rates, child-woman ratios and total fertility for the early decades of Independence, although pre-independence regional estimates have not shown considerable differences (Irudaya Rajan 2005, 26). It seems that in some southern areas, most notably in Kerala, fertility was lower than in the North already in the 1950s. It remains unclear whether that was due to a very early onset of fertility decline in those areas or whether the comparatively lower level of fertility was a perennial feature of some areas (Irudaya Rajan 2005; Guilmoto and Irudaya Rajan 2001). Marriage is still nearly universal in India, only 1 percent of women in the age group 45-49 having never been married (IIPS 2007). As age at marriage is also staying low - median age at first marriage for the age group $20-24$ being 18.3 years (Véron 2008,29 ) - birth rates remain relatively high (Crude Birth Rate is 23 per thousand, IIPS 2007).

3 The National Family Health Survey (NFHS) is a nation-wide survey that has been carried out three times (19902, 1998-9, 2005-6), corresponding to the Demographic and Health Surveys. Interviews were conducted with nearly 200,000 respondents (124,385 women age 15-49 and 74,369 men age 15-54) from 29 states of India. 


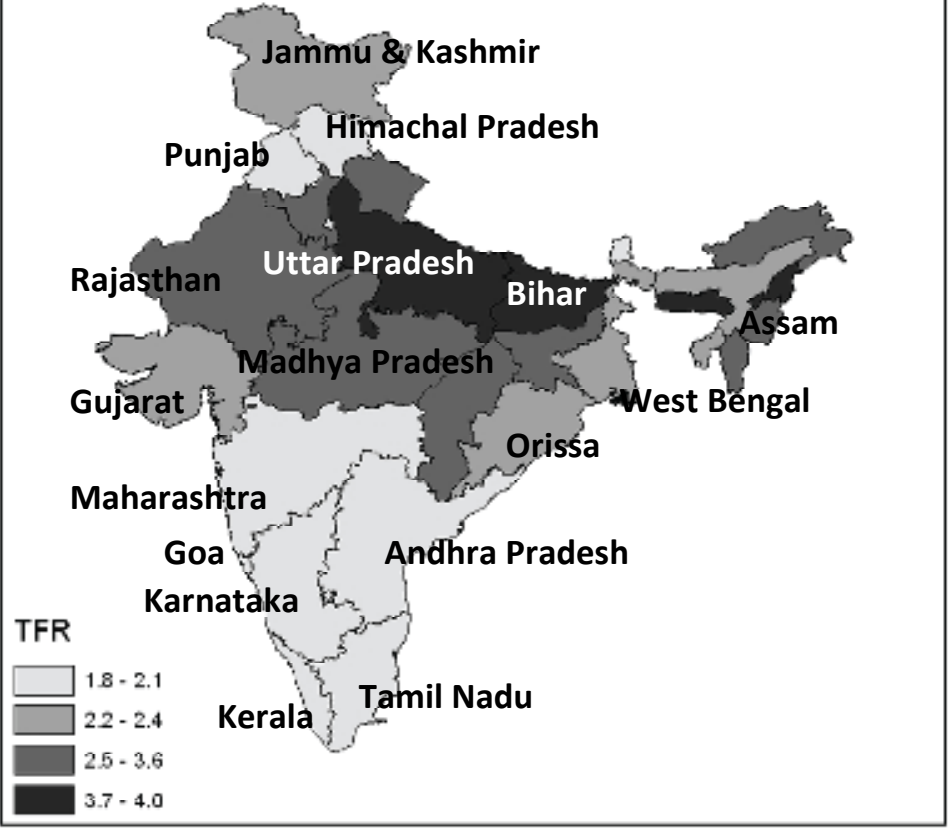

Figure 1. State-wise Total Fertility Rates in India, major states named. Source: National Family Health Survey 2005-6 (IIPS 2007).

\section{Economic development and poverty}

Many demographers have carried out regression analyses in order to determine which variables best account for the stark regional fertility differentials in India, based on district ${ }^{4}$ level census data (Malhotra, Vanneman and Kishor 1995; Murthi, Guio and Drèze 1995; Bhat 1996; Drèze and Murthi 2001; Guilmoto 2005; Bhattacharya 2006; Chakrabarty and Guilmoto 2005 used village-wise census data; Dommaraju and Agadjanian 2009 used NFHS-2 data; see Table 1). Most of these studies used census data 1981 and 1991 and thus give a somewhat dated picture of the determinants.

4 India has 37 states and union territories which are divided into 626 districts. 
Table 1. Factors explaining district-wise fertility differentials in India, according to different regression analyses. (Restricted to factors that were found significant at 1 percent; significant factors that were found insignificant or received values of opposing direction in some other regression analysis are left out).

\begin{tabular}{|l|l|}
\hline Literacy & female and male literacy \\
\hline Gender asymmetry & $\begin{array}{l}\text { son preference } \\
\text { sex ratio (F/M) }\end{array}$ \\
\hline Facilities & $\begin{array}{l}\text { clean water availability } \\
\text { educational facilities }\end{array}$ \\
\hline Economic development & agricultural productivity \\
\hline Religious, cultural and regional factors & $\begin{array}{l}\text { proportion of Muslims } \\
\text { proportion of Christians } \\
\text { region (South or North India) }\end{array}$ \\
\hline Family structures & proportion of joint families \\
\hline
\end{tabular}

Sources: Malhotra et al. 1995; Murthi et al. 1995; Bhat et al. 1996; Drèze and Murthi 2001; McNay et al. 2003; Guilmoto 2005; Chakrabarty and Guilmoto 2005, Bhattachariya 2006.

According to Drèze and Murthi (2001), aggregate level indicators of overall development, such as male literacy, urbanization and poverty reduction bear no significant association with district-wise differences in fertility in the Indian context. Economic variables seem to play only modest role, and in some regression analyses the researchers failed to find any significant relationship between poverty level or urbanization and fertility (Murthi et al. 1995; Drèze and Murthi 2001).

In Chakrabarty and Guilmoto's (2005) village-level regression analysis of the South Indian states, some economic factors pointing to general development of rural economy did appear as significant at 1 percent: proportion of agricultural labourers (positively associated), proportion of irrigated land (negatively associated) and average settlement size (negatively associated). However, in their regression model, socio-demographic variables affect fertility rate more significantly than these variables related to economic development. Guilmoto (2005) concludes that no matter if differences between villages, districts, states or even more generally between larger regions such as south, north, central, east and west India are examined, the level of economic development in the aggregate level is far from a strong influencing factor in fertility decline. James and Subramanian (2005) carried out a multilevel analysis of fertility in the state of Andhra Pradesh and concluded that even after taking socio-economic factors into account, local and endogenous factors remain as triggers of fertility decline. Also Dommaraju 
and Agadjanian (2009) show the persistence of spatial variations in fertility intentions and births, net of economic and women's status factors, in their analysis of NFHS-2 data from 1998-9.

When comparing women living in poor households and those in middle income and better off households, the correlation between economic well-being and fertility appears self-evident. In all contexts, local differences between economic classes exist. The picture becomes more complicated if we look at the magnitude of differences between socio-economic groups in their fertility levels in different contexts. In Andhra Pradesh the difference between urban and rural fertility is only around 10 percent while the difference is more than 25 percent in all-India level; between the fertility of the poorest and the wealthiest differs only by 13 percent while in the all-India level the difference is 45 percent. TFR of the illiterate women is only 4 percent lower than the average, compared to 22 percent in India (NFHS-2 data, Guilmoto 2005, 415-6). This narrowing of fertility differentials has been spectacular despite the relatively low level of social and economic development in Andhra Pradesh: female literacy was below national average in 2001 census, the per capita income was below national average, and infant mortality rate is higher than in other South Indian states (James and Subramanian 2005, 358). The case of Andhra Pradesh manifests idiosyncratic features: the predictive power of conventional factors such as female literacy and infant mortality rate for fertility variation within the state is low (ibid., 381).

All in all, neither the regional difference between southern and other parts of India in fertility levels nor district-wise variation can be easily explained away in regression analyses by differences in economic or social development. The economic dynamism manifested in the South has undeniably had an effect, in enabling fertility decline, even if it has not been the determining factor for variation. The well-known case of Kerala is an example of socially-induced fertility transition in a context of slow economic development (Irudaya Rajan 2005, see Table 2), while in the northern Punjab the dynamic economic situation evidently lies behind the decline in fertility levels. James and Subramanian (2005) discuss in length the various poverty alleviation and welfare schemes and the Public Distribution System of food grains which has had an important effect for the conditions of living for the rural masses in Andhra Pradesh, in a state where the proportion of abnormally thin women and stunted children witnesses to widespread poverty (see Table 2 below). James and Subramanian (2005) included a number of variables measuring the effects of government development interventions in their multi-level regression analysis, but the number of beneficiaries per household surprisingly turned out to have a positive relationship with fertility. This could be caused by the fact that government schemes target particularly the poorest areas where contraceptive prevalence is low. 
Table 2. Some socio-economic and demographic indicators of India and the states of Kerala and Andhra Pradesh 2005-6.

\begin{tabular}{|l|c|c|c|}
\hline & India & Kerala & $\begin{array}{c}\text { Andhra } \\
\text { Pradesh }\end{array}$ \\
\hline Total Fertility Rate & 2.68 & 1.93 & 1.79 \\
\hline Under-five mortality rate, \%o & 74 & 16 & 63 \\
\hline Female literacy rate, \% & 55 & 93 & 50 \\
\hline Women employed any time during the last 12 months, \% & 43 & 30 & 52 \\
\hline GNP per capita, US\$, 2006-7 & 697 & 824 & 684 \\
\hline Proportion of abnormally thin women (BMI <18.5), \% & 36 & 18 & 34 \\
\hline $\begin{array}{l}\text { Proportion of stunted under-five-year-olds (height-for-age; } \\
\text { WHO standard), \% }\end{array}$ & 48 & 25 & 42 \\
\hline Women aged 18-29 who were married by exact age 18, \% & 46 & 17 & 56 \\
\hline Median age at female sterilization, years & 25.5 & 26.5 & 23.3 \\
\hline
\end{tabular}

Source: IIPS 2007.

Although the influence of economic development on fertility levels cannot be proved by multivariate analyses, it is evident that for fertility to decline, some potential economic opportunities for improvement have to be opened up. They give people a sense of change even in poverty conditions. In Andhra Pradesh, some indicators of socio-economic development are slightly above the all-India level (under-five mortality rate, women's labour force participation rate, the proportion of abnormally thin women and stunted children) while some others are worse (GNP per capita, female literacy rate; see Table 2). Säävälä’s (2001) qualitative case study in Andhra Pradesh claims that what is at issue is people's belief in their right to a better future for their children and the existence of some opportunities, even if they are not realized in many villagers' lives. If the economy is very stagnant and rigidly reproducing existing social and political inequalities, people do not easily change their fertility behaviour. The rationale for fertility control may be different in different socio-economic groups in varying contexts: in Tamil Nadu (Krishnamoorty, Kulkarni and Audinarayana 2005; Kishor 1994) as well as in Andhra Pradesh (Säävälä 2001), fertility decline among the poor is understandable as people's attempt to abstain from further immiseration and aspirations for inter-generational upward mobility in conditions of changing qualityquantity trade-off related to children. 


\section{Child mortality}

Persistent and massive mortality decline is the "remote cause" which has ultimately caused all sustained fertility declines since the 18th century (Dyson 2002). Although the southern states have both lower fertility and child mortality than the northern states, the relationship between child mortality and fertility is far from straightforward, instead producing a somewhat erratic trajectory over time. In some periods in some states, decline in child mortality rate has not been reflected in TFR decline, on the contrary (Véron 2008, 41).

Regression analyses using child mortality as an explanatory variable show a clear connection between fertility and mortality in India. Guilmoto $(2005,403-5)$ examined four district-level analyses of fertility in India 1981-2001 and found that in all of them male child mortality had a positive correlation coefficient, in three studies out of four the relationship was significant at 1 percent (Malhotra et al. 1995; Bhat 1996; Guilmoto 2005) and in one at 5 percent (Drèze and Murthi 2001). In regression analysis carried out by Ramachandran and Ramesh (2005) to study how some socioeconomic and infrastructure variables explain fertility differentials in village level of analysis in the state of Andhra Pradesh, child mortality appears a significant explanatory variable although not even closely as significant as female literacy, for example. The same was found by James and Subramanian (2005). Under-five mortality in India has declined from 109 in 1990-2 to 74 per 1,000 in 2005-6. However, the situation remains worse in some high-fertility states, highest being Uttar Pradesh (96\%), compared to the lowest in Kerala (16\%). Andhra Pradesh leans towards the higher end of the Indian child mortality spectrum with a figure of 63\% (IIPS 2007) despite being the state with the lowest Indian TFR. Declining trend in child mortality is evidently one of the necessary conditions for a pronounced fertility decline even if it is not among the most important correlates in all contexts.

In Bhattacharya's (2006) study which analysed census data from 1981 and 1991, nearly half of the decline in TFR between censuses was caused by reduction in child mortality. The study examined factors behind child mortality as well, and such features as provision of safe drinking water, paved roads to nearest city and medical facilities contributed nearly 40 percent of the total inter-decadal decline in child mortality. Growing female literacy and work participation rates accounted for only 6 percent of the child mortality decline. Female autonomy variables were marginal in explaining fertility and mortality decline as well. This is why Bhattacharya is confident in stating that variables directly related to socio-economic development and modernization have had the greatest impact in reducing fertility and child mortality in all-India level between 1981 and 1991 (ibid., 279). However, his analysis does not necessarily explain the specific fertility decline to below replacement-level since 1991; the configuration of explanatory models may have changed. 


\section{Literacy and education}

Literacy, particularly female literacy, is known to explain fertility decline in various developing parts of the world; educational differentials are among the most widely studied fertility differentials (Bongaarts 2003). In India, male literacy does not have as clear correlation as female literacy with fertility, for example Drèze and Murthy (2001) did not find any significant negative correlation in district level between male literacy and fertility. In Dwivedi's and Sogarwal's (2008) study which used data from the NFHS-2 in 1998-9, the likelihood of contraceptive use among higher educated women is higher, while the education of men did not have as strong influence. All studies in the district level witness to the inverse relationship between the level of female literacy and fertility. The level of a woman's education and her fertility appear to have a very clear connection on individual level as well: in 2005-6 National Family Health Survey, illiterate women had a TFR of 3.55 while women with 12 years or longer education had a TFR of 1.8 (Véron 2008, 36).

Chakrabarty and Guilmoto $(2005,349)$ show that in the similar manner that highly educated women are usually the social forerunners in fertility decline, also villages where female literacy is relatively higher compared to the surrounding area are regional forerunners in fertility decline. The simple correlation between education and fertility is nevertheless not a very satisfactory method to assess literacy and education as a determinant of fertility decline. The relationship between education and fertility differs considerably between areas; as mentioned above, in areas of low fertility the difference between educational groups narrows down (Guilmoto 2005).

Some researchers have raised skeptical views on the nature of interrelatedness between female literacy and fertility, based on the failure of the factors to be interlinked in individual level in some regions or case studies (e.g. Jeffery and Basu 1996; Jeffery and Jeffery 1996; Vlassoff 1996). Drèze and Murthi's (2001) careful district-wise regression analysis nevertheless yields a consistent picture of the relationship between female literacy and fertility in aggregate level. The association remains significant even when allowing for other factor such as male literacy, poverty, urbanization, caste, and religion. They used a fixed-effects model in the analysis in order to rule out a spurious relationship, that female literacy and lowered fertility could be driven by some common third factor. They conclude that decline in child mortality and improvement in female literacy together explain half of the fertility decline in India between 1981 and 1991.

Although female literacy and educational level more generally is a very strong candidate for the most important variable in explaining district-wise differences in fertility transition, some demographers (e.g. Bhat 2002, McNay et al. 2003) are convinced that the uneducated women's fertility and contraceptive decisions are the critical factor in the demographic future of India. Bhat (2002) noted that almost half of the fertility decline in India in the 1980s was due to fertility decline among illiterate women, and in the 1990 s even more, 65 percent. 


\section{Reproductive health services}

Could the regional differences in the trajectory of fertility decline and the spectacular drop in period TFR in the South be explained by better family planning and reproductive health services? One of the reasons why reproductive and other health services are a good candidate for a factor affecting fertility levels is the fact that in the federal state of India, state governments are relatively free to implement their own health policies. Despite the central government formulating general principles, states may choose their own ways of realizing the objectives.

The empirical evidence of the relationship between health services and fertility is nevertheless contradictory. Murthi, Guio and Drèze (1995) found that access to public health services reduced child mortality but had no significant, independent effect on fertility. By using geographical analysis, Guilmoto (2005) showed that fertility differentials do not follow administrative borders in any meaningful manner. A 'border-effect' could be expected if the service provision would be among the important determinants of fertility levels. He also carried out a two-stage regression analysis which showed that the initial clear correlation coefficient between maternal and child health variables and fertility disappeared when the model was added with a variable on the frequency of visits by health workers, which was considered as a non-endogenous instrument independent of the fertility decisions of particular women. Although such indicators as proportion of institutional deliveries or antenatal check-ups negatively correlate strongly with fertility, the relationship is largely endogenous and does not give grounds to claim that the supply of health services per se would have an independent impact on reproductive behaviour. Women who make use of reproductive health services may be precisely the women who have already opted for fertility regulation, and the use of maternal and child health services may reflect a demand for such services that is an outcome of the same social realities that created willingness to limit family size in the first place.

The study in the southern state of Tamil Nadu (Srinivasan and Kumar 2005, 312), nevertheless shows that the increased access to primary health care services which is manifested in the density of medical and paramedical personnel (both private and public), is an important factor contributing to the decline in child mortality, greater acceptance of contraception and consequently decline in fertility levels, after controlling for demand-generating, socio-economic factors. It appears commonsensical, that in order to limit the number of births efficiently and reaching below replacement-level fertility in a population of universal and early marriage, efficient contraceptive methods must be available. They can only be adopted if health services respond to the demand even if it is difficult to prove that they would create demand for family planning.

Guha and Datta's (2008) study used a regression model to study district-wise differences in fertility in the state of Madhya Pradesh in central India. The results of regression analysis show that the strength of family welfare programmes in reducing fertility is 
more important than that of socio-economic development. Women residing in areas with a strong family welfare programme are likely to have lower fertility compared to those in areas with a weak programme. Neither socio-economic development nor status of women exerted a similar influence on fertility decline in Madhya Pradesh.

The most interesting feature of the South Indian below replacement-level fertility decline is that it is brought about with the practically sole reliance on female sterilization as the fertility regulating technique. In the state of Andhra Pradesh, for example, the proportion of all currently married women being sterilized is 62 percent, and in rural areas even higher than that. Sterilization is not only a method taken up in the later stages of reproductive career, but very early in married life. In Andhra Pradesh, 95 percent of the sterilized women had never used any other contraceptive method before the operation, which partly reflects the fact that women are not offered alternative methods by the health personnel: in 2005-6, only 14 percent of sterilization acceptors had been informed about other contraceptive options (IIPS 2007). The median age of getting sterilized among women who had had the operation during the last 10 years preceding the survey, was 23.3 years in A.P. (national average is 25.5 years). Because sterilization is the major contraceptive method in Andhra Pradesh, the extremely low TFR of 1.79 can hardly be thought to be the outcome of some period effect that would have suppressed fertility aspirations and postponed pregnancies. Also data on men's and women's future fertility aspirations tell that 92 percent of men and women who had 2 children in Andhra Pradesh did not want any more children. It is noticeable that in the state sharing the lowest TFR in India with Andhra Pradesh - Goa - only 76 percent of fathers and 83 percent of mothers of two children wanted no more children at all (NFHS-3 data, IIPS 2007).

The combination of below replacement-level fertility, low age at marriage (see below) and reliance on female sterilization as a contraceptive method has led to a very peculiar Age-Specific Fertility in Andhra Pradesh. In recent years, largely attributed to increase in the use of irreversible methods, the age pattern of childbearing in India has been changing to a very peaked pattern, which has in Andhra Pradesh become the most extreme of any society in the world (Matthews et al. 2009; see Figure 2). The sharpness of the ASFR was already visible in the village study by Säävälä (2001) which described a case study of a rural, low fertility area in the mid-1990s. In Säävälä's qualitative study, young married women considered the compression of fertility career as desirable: they saw early marriage generally as preferable so that the ambiguous and vulnerable period between maturity and marriage could be minimized. Early childbirth was desirable to prove their reproductive potential to the in-laws, while limiting the number of children to two (but having at least one son) was necessary in order to reduce the feared risks related to pregnancy and childbirth and being able to feed and educate their children better. Earliest possible sterilization was sought to cut short the troublesome reproductively active age period and to 'cool' their bodies (Säävälä 1999, 2001, 2006). The squeezed and very early reproductive period in Andhra women's lives does not in itself raise culturally 
motivated, ethical objections although it might not be desirable from a public health or demographic point of view (Matthews et al. 2009; Padmadas, Hutter and Willekens 2004). Very early childbearing feeds to population growth, increases physiological risks in childbirth and pregnancy, and worsens women's and newborn nutritional and health status. The co-existence of very early marriage age and below replacement-level fertility shows that the universalizing theory of the first and second fertility transition that ties fertility decline below replacement-level together with changes in marriage patterns and later on, individuation (Lesthaeghe 2010) or individualism (Ariès 1980) does not appear to hold in the case of South India.

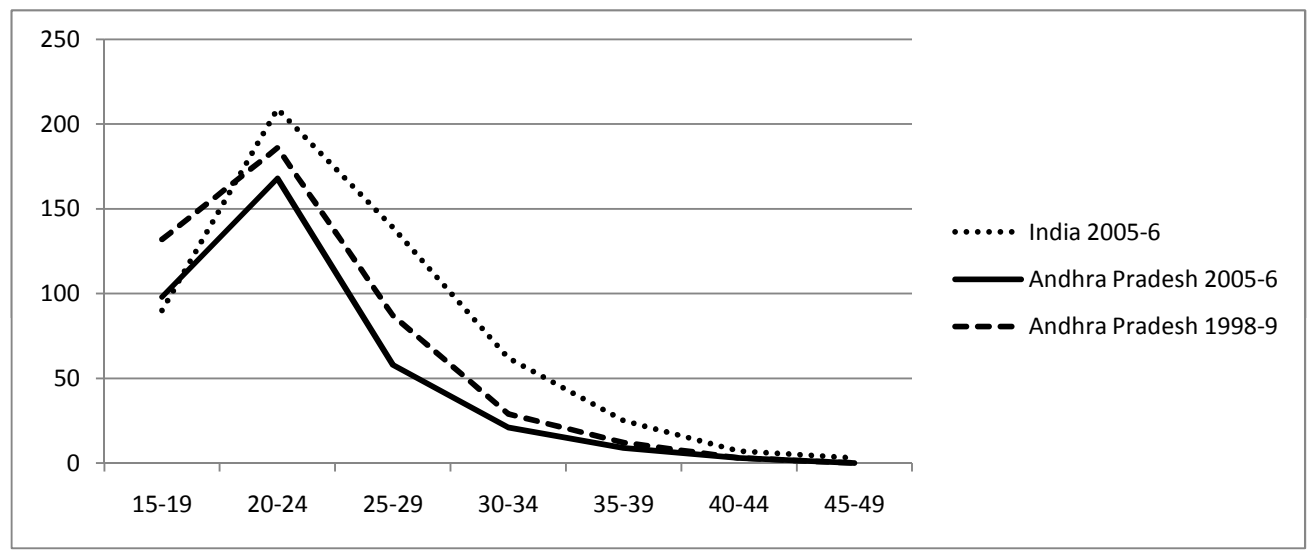

Figure 2. Age-Specific Fertility Rates per thousand in India 2005-6, state of Andhra Pradesh 2005-6 and 1998-9. Sources: IIPS 2007; IIPS 2000.

\section{Gender asymmetry}

People in the South share certain traditional marriage and kinship practices that separate them from people in other parts of the country. Most notably, cross-cousin and uncle-niece marriages and village endogamy have been accepted and even encouraged among many South Indian Hindu castes, unlike among Hindus in most other parts of the country (see Säävälä 2001). Dyson and Moore (1983) considered these features as manifestations and causes of the relatively better female autonomy in southern India. They proposed that the lower fertility levels prevalent in the South are accountable to better female autonomy and kinship structure. The South has been described as more equitable not only based on cultural norms (e.g., Dyson and Moore 1983; Basu 1992), but also due to women's higher labour participation in the South compared to North and public interest in policies that support women (Jefferey 1993).

Differing gender equity between North and South India was examined as a determinant of fertility by Rahman and Rao (2004). The results of a comparison of survey 
data between Uttar Pradesh and Karnataka, two stereotypically northern and southern states, shows that the actual kinship practice in southern India may have changed considerably since Dyson and Moore wrote their analysis in the beginning of 1980s, or at least not applicable to all of South India. Women in the southern study area were not unambiguously more autonomous than women in the northern study area. The level of village exogamy was nearly the same in both areas and in the South, the prevalence of marriages among relatives was low, contrary to the common belief. Those who were married to a relative had less, not more, autonomy in their movements, fertility decisions and household decisions. Southern women generally had less influence in household finances than women in the North, although they had more freedom of movement and decision-making power in fertility. Rahman and Rao's (2004) refutation of the difference between southern and northern female autonomy and its relationship to fertility should nevertheless be specified: first, the prevalence of cousin marriages in South India is district and caste specific and the survey they carried out in Karnataka may not have been representative of the situation in all of southern India. Although Rahman and Rao's (ibid.) study is a sobering reminder of the complex relationship between female autonomy and fertility, the general social valuation of femininity and women in Southern India might have escaped their household-level analysis.

The examination of female autonomy, defined as an ability to act without the interference or permission of some other actor, was examined by Dwivedi and Sogarwal (2008). They used a three-fold concept of female autonomy, viz. physical autonomy (freedom of movement), economic autonomy (earning and decisions concerning the use of income) and decision-making autonomy (individual or joint decisions concerning e.g. own health or cooking). They found that physical and economic autonomy plays a positive association with contraceptive use rate, whereas a contrary association was found between decision-making autonomy, even after controlling for sociodemographic and other variables. The contradictory result of the regression analysis may partly reflect the rather vaguely distinguished three sub-types of variables. However, in similar vein as Rahman and Rao's (2004) analysis, Dwivedi and Sogarwal's (2008) study reminds that the issue of women's autonomy or women's status is far from straightforward in terms of fertility and contraception.

In India, Muslims have higher fertility than Hindus, who form the majority. Although the fertility differentials between Hindus and Muslims in India can be largely accounted by Muslims' relatively lower educational status and poorer economic standing, the difference does not disappear altogether by controlling these context variables (Dharmalingam \& Morgan 2004). This unexplained difference has prompted a number of interpretations, for example the allegedly poorer women's autonomy and gender discrimination among Muslims. However, research does not support this view (Morgan et al. 2002; Dharmalingam \& Morgan 2004). Dharmalingam and Morgan (ibid.) consider the political-economic minority role of the Muslims to be the most plausible 
explanation to the higher fertility aspirations of this group. Although in regression analyses the proportion of Muslims has a significant correlation coefficient with fertility in the district level, it fails to explain wider regional fertility differentials. In Kerala, where fertility transition first started in India, 24 percent are Muslims compared to the all-India percentage of 13. In the high-fertility Madhya Pradesh, only 6 percent are Muslims, while in low-fertility Andhra Pradesh 9 per cent.

Women's early age at marriage is one of the factors that relates to gender asymmetry and affects fertility directly. Low age at marriage as a proximate determinant of fertility is known to create a tendency to higher lifetime fertility and also to be partly responsible for rapid population growth (Padmadas et al. 2004). Motherhood is nearly universal for women in India: only 3 percent of women aged 45-49 have never given birth (IIPS 2007). This feature is shared everywhere in India, only urban areas manifesting a marginally larger proportion of women remaining unmarried or childless. There are regional differences in the age at marriage so that in the North, women generally marry earlier than in the South.

However, in Andhra Pradesh age at marriage is as low as in many high fertility North Indian states. In NFHS-3 (2005-6), 56 percent of women aged 18-29 were first married by exact age 18 (legal minimum age) in Andhra Pradesh. This is higher than the Indian average (46 percent) and of same extent as in North Indian high fertility states such as Uttar Pradesh (52 percent). The other South Indian states differ from Andhra Pradesh markedly in this regard: the percentage of young women having married by exact age 18 in Kerala was 17, and in Tamil Nadu 25 (IIPS 2007). The age at first marriage has been slowly increasing. This most probably reflects the rising educational attainment of women: the longer women and girls study, the later they marry. This also explains the somewhat changing form of the ASFR graph (see Figure 2) in the young age cohorts between 1998-9 and 2005-6.

Female sterilization is the major modern contraceptive method used in India. In three out of the four southern states (Andhra Pradesh, Karnataka, and Tamil Nadu) 90 percent or more of contraceptive users have adopted female sterilization (IIPS 2007). Padmadas et al. (2004) show that in Andhra Pradesh, the early adoption of sterilization together with the slowly rising age at marriage has led to dire compression of the effective reproductive span (duration between first marriage and menopause or sterilization of the woman or her spouse). The median age at female sterilization in Andhra Pradesh was 23.3 years according to NFHS-3 (2005-6), which was 2.2 years lower than the all-Indian average (IIPS 2007). The median age at female sterilization had continued to decline since NFHS-2 in $1998-9$ by 0.3 years. This reflects the lowering fertility aspirations: when female sterilization is the only easily acceptable contraceptive method available and age at marriage remains low, the age at sterilization declines as an outcome of women's willingness to secure fertility control. According 
to Padmadas et al.'s (2004) life table analysis, the marriage cohort 1990-6 has a mean expected effective reproductive span of only 4.5 years. The fact that women marry early, have their children narrowly spaced, and opt for sterilization at a very young age in their early 20s, has considerable demographic and socio-economic effects (Padmadas et al. 2004; Matthews et al. 2009). Apart from health and nutritional effects, the lengthening period in female life of being freed from childbearing and immediate child care obligations gives leeway to other activities, for example in adult education and waged employment.

\section{Regional and diffusion effects}

As the above review shows, fertility differentials and fertility transition to below replacement-level fertility in some states in India fails to be easily explained away by the usual socio-economic or demographic variables. According to Drèze and Murthi (2001), the very powerful explanatory variables such as female literacy and child mortality still leave space for other effects in regression analyses. They consider as potential explanations for the remainder of the variation inter-district diffusion effects, the expansion of family planning programmes, and the delayed effect of earlier improvements in economic and social conditions. Also according to Guilmoto (2005), socio-economic and demographic variation does not empty the regional variation. $\mathrm{He}$ sees the diffusion effect, a geographical spread from certain innovative nodal areas towards the peripheries, as most promising attempt to find better understanding on the differences in fertility transition. The regional difference is far from residual. It is as significant as those ascribed to the main sociodemographic factors of fertility, such as female literacy and child mortality (ibid. 411). Guilmoto's modeling for 2001 showed a residual difference between North and South, cleaned of differences in socioeconomic variables, to be nearly 1.4 children per woman. Regional differentials remain a 'black box'.

Diffusion, a concept that has become keenly adopted by a number of demographers who have become more and more disillusioned of the usefulness of socio-economic determination of fertility (e.g. Casterline 2001), can mean from a social perspective two things: social learning and social influence. In terms of learning, diffusion refers to the acquisition of knowledge and information from others, either impersonally through mass media or interpersonally in social networks. Social influence in turn refers to such phenomena as peer pressure, authority or status emulation. Diffusion may progress independently of and faster than socio-economic development, although the two processes are necessarily complementary (McNay et al. 2003, 22). However, Kravdal (2003) warns against too simplistic forms of measuring imitation effect; according to him, an "imitation effect" can quantitatively only be estimated under very special assumptions that in practice will be hard to defend. 
In the fertility decline of the uneducated women examined by McNay et al. (2003), it is evident that the decline among this socio-economic group is not explained away by reference to indicators of their individual circumstances or characteristics. There is a strong influence detectable from the fertility behaviour of the others, be they in the same household or in the local community. The positive role of educated others and media exposure remain significant at the household and indvidual levels in their regression analysis. The community influence also works the other way round: in communities characterised by strong son preference, this seems to be a significant obstacle to contraceptive use by uneducated women, no matter what their individual or household characteristics. However, even McNay et al.'s (2003) finely-tuned modelling is unable to fully account for why the uneducated women appear to be strongly influenced by other contracepting women in their household and the wider society around them. Multivariate analysis might not be a very useful way to examine social diffusion.

Bongaarts (2003) shows in his macro-level analysis of 57 less developed countries, that in the later stages of fertility decline, the difference between educational groups in their realized fertility diminishes. However, the difference in unwanted fertility tends to rise. This would lead us to infer that the ideal model of lower fertility is diffusing faster than the knowledge and practice of fertility control: social influence is stronger than social learning. It is nevertheless to be noted that the case of starkly lowered fertility among the illiterates in some parts of India, most notably in Andhra Pradesh, shows that in case family planning methods and services are available, the situation may be quite different. This was also noted by Bongaarts (2003) in the case of Indonesia, Thailand and Vietnam, where, unlike in most other developing countries examined, the differences in unwanted fertility between educational groups were very small and generally low. Family planning and reproductive health services are thus closely interacting with the processes of social and geographical diffusion.

Diffusion is a process that can be examined in micro or macro level, as a social process of learning and influence, or as a geographical effect between certain centres and peripheries. Bocquet-Appel et al. (2002) compared the diffusion of fertility regulation in historical Europe to the process in India by geographical methods and models. In Europe, both social and geographical processes served as the transmission channels of transition at its onset. In India, the situation appears very different in terms of diffusion: according to Bocquet-Appel et al. (ibid.), the diffusion is non-geographical. The sudden and widespread change they observed during 1971-81 suggests another form of diffusion, occurring from a centre and directed towards all informationreceivers, irrespective of their geographical and social location. This kind of process has been identified and named "top-down" by Srinivasan (1995). Bocquet-Appel et al. (2002) thus stress the importance of the centrally-led family planning policies as the driving force behind fertility decline. This view is supported by the observation that in southern parts of India, maternal and child welfare programmes appear to be 
functioning relatively better than in many north Indian areas. However, some regression and geographical analyses do not support this view of the role of population policies and maternal and child health policies (see above; Guilmoto 2005).

Despite the lack of convincing evidence, we could hypothesize a relationship to exist between family welfare and health policies and practices and fertility decline in a more general contextual level, which is more difficult to operationalize for the purposes of multivariate analysis. As Dommaraju and Agadjanian (2009) state, changes in fertility desires and their actualization in different communities and areas may be better understood when situated within the broader socio-political context. The problem for statistical analysis remains: diffusion is more a post facto description of a process and cannot provide predictions.

\section{Discussion}

The examination of empirical studies on the determinants of the first fertility transition and regional fertility differentials in India shows the difficulty of pinpointing any simple and straightforward trajectories. Fertility can decline, even below replacement-level, despite relatively slow socio-economic development: when a significant proportion of the population lives in absolute poverty and hunger, large proportion of women are still illiterate, child death continues to be a risk, and the economy is largely agriculturebased. The realization of decline in child mortality and rising female literacy appear to be necessary conditions of fertility decline in the Indian context. However, they are not sufficient explanations and neither similarly powerful in all contexts. In the case of South India versus North India we see that favourable conditions for social and economic development have to be politically created so that even the poor and the uneducated can consider fertility to be in the realm of conscious choice. The influence of reproductive health services has not been unanimously shown to be determining in empirical studies although some studies point to the importance of health services in fertility decline. This should not hinder from sight the fact that health services as well as social and economic development in basic amenities such as food, clean water, and roads helps to reduce child mortality and thus has an important role for wellbeing and in bringing fertility down, even if their direct effect on fertility levels cannot be unanimously proven in multivariate analyses. While social and economic conditions may pave the way for fertility decline even to below replacement-level in a developing country, it is to be noted that a diffusion effect, social learning and influence, may work better in some contexts than in others. The plurality of processes makes decontextualized analysis tricky. This is why context-specific qualitative case studies are important and cannot be replaced by register and sample survey based data analysis alone.

The case of Andhra Pradesh shows that fertility decline can be achieved despite slow social development and gender asymmetries, in case some of the basic manifestations 
of human development (child mortality, women's literacy) have begun to improve. Geographical and social diffusion effects are partly responsible for the speed of the transition, although they are difficult to measure or test in the level of decision-making.

\section{References}

Ariès, Philippe. 1980. Two successive motivations for the declining birth rate in the West. Population and Development Review 6(4):645-650.

Basu, Alaka Malwade. 1992. Culture, the Status of Women, and Demographic Behaviour. Illustrated with the case of India. Oxford: Clarendon Press.

Bhat, P. N. Mari. 1996. Contours of fertility decline in India: A district-level study based on the 1991 census. In: Population Policy and Reproductive Health, edited by K. Srinivasan, pp. 96-179. New Delhi: Hindustan Publishing Corporation.

2002. Returning a favor: Reciprocity between female education and fertility in India. World Development 30(10): 1791-1803.

Bhattacharya, P. C. 2006. Economic development, gender inequality, and demographic outcomes: Evidence from India. Population and Development Review 32(2):263291.

Bocquet-Appel, J.P., Irudaya S. Rajan, J. N. Bacro and C. Lajaunie. 2002. The Onset of India's Fertility Transition. European Journal of Population 18(3):211-232.

Bongaarts, J. 2003. Completing the fertility transition in the developing world: The role of educational differences and fertility preferences. Population Studies 57(3):321-336.

2008. Fertility transitions in developing countries: Progress or stagnation? Studies in Family Planning 39(2):105-110.

Casterline John B. 2001. Diffusion Processes and Fertility Transition: Introduction. In: Diffusion Processes and Fertility Transition: Selected Perspectives, edited by John B.Casterline, pp. 1-38. National Research Council, Committee on Population, Division of Behavioral and Social Sciences and Education. Washington, DC: National Academy Press.

Chakrabarty, Manisha and Christophe Z. Guilmoto. 2005. An analysis of the determinants of fertility behaviour in South India at the village level. In: Fertility Transition in South India, edited by Christophe Z. Guilmoto and S. Irudaya Rajan, pp. 324-356. New Delhi: Sage.

Das Gupta, M. and P.N. Mari Bhat. 1995. Fertility decline and increased manifestation of sex bias in India. Population Studies 51(3):307-315.

Dharmalingam, A. and S. P. Morgan. 2004. Pervasive muslim-hindu fertility differences in india. Demography 41(3): 529-545.

Dommaraju, P. and V. Agadjanian. 2009. India's North-South divide and theories of fertility change. Journal of Population Research 26(3):249-272.

Dorius S. F. 2008. Global demographic convergence? A reconsideration of changing intercountry inequality in fertility. Population and Development Review 34(3):519537. 
Doskoch P. 2008. Fertility declines have stalled in many countries in Sub-Saharan Africa. International Family Planning Perspectives 34(3):149-150.

Drèze, J. and M. Murthi. 2001. Fertility, education, and development: Evidence from India. Population and Development Review 27(1):33-63.

Dwivedi L. K. and R. Sogarwal. 2008. Understanding contraceptive adoption in India: Does women's autonomy matter? Journal of Family Welfare 54(1):24-34.

Dyson, Tim. 2002. On the future of human fertility in India. In: Completing the fertility transition. United Nations, New York, USA, pp. 392-408. Available in http://www. un.org/esa/population/publications/completingfertility/RevisedDysonpaper.PDF

Dyson, T. and M. Moore. 1983. On kinship structure, female autonomy and demographic behavior in India. Population and Development Review 9(1):35-60.

Erfani, A. and K. McQuillan. 2008. Rapid fertility decline in Iran: Analysis of intermediate variables. Journal of Biosocial Science 40(3):459-478.

Gereltuya, A. 2008. Dramatic fertility transition in Mongolia and its determinants: The demise of the pronatalist state. Asia Pacific Population Journal 23(2):81-99.

Guha, Mohua and Subhra Datta. 2008. Development, status of women and demographic outcomes in Madhya Pradesh: A regional analysis. Journal of Social Sciences 16(1):1-12.

Guilmoto, Christophe Z. 2005. Fertility decline in India: Maps, models and hypothesis. In: Fertility Transition in South India, edited by Christophe Z. Guilmoto and S. Irudaya Rajan, pp. 385-435. New Delhi: Sage.

Guilmoto, Christophe Z. and Irudaya Rajan, S. 2001. Spatial patterns of fertility transition in Indian districts. Population and Development Review 27(4):713-738.

------. (eds). 2005. Fertility Transition in South India. New Delhi: Sage.

International Food Policy Research Institute (IFPRI). 2009. India State Hunger Index: Comparisons of Hunger Across States, by Purnima Menon, Anil Deolalikar and Anjor Bhaskar. Washington, D.C., Bonn, and Riverside: International Food Policy Research Institute (IFPRI), Welthugerhilfe and University of California, Riverside.

International Institute for Population Sciences (IIPS) and ORC Macro. 2000. National Family Health Survey (NFHS-2), 1998-99: India. Mumbai: IIPS.

International Institute for Population Sciences (IIPS) and Macro International. 2007. National Family Health Survey (NFHS-3), 2005-2006: India. Vol 1. Mumbai: IIPS.

Irudaya Rajan, S. 2005. Introduction: Emerging demographic change in South India. In: Fertility Transition in South India, edited by Christophe Z. Guilmoto and S. Irudaya Rajan, pp. 23-49. New Delhi: Sage.

James, K. S. and S. V. Subramanian. 2005. Decline in fertility in Andhra Pradesh: A reexamination of conflicting arguments. In: Fertility Transition in South India, edited by Christophe Z. Guilmoto and S. Irudaya Rajan, pp. 357-384. New Delhi: Sage. Jeffery R. and A. M. Basu. (eds.) 1996. Girls'Schooling, Women's Autonomy and Fertility Change in South Asia. New Delhi: Sage.

Jeffery P. and R. Jeffery. 1996. What's the benefit of being educated: Women's autonomy and fertility outcomes in Bijnor. In: Girls 'Schooling, Women's Autonomy 
and Fertility Change in South Asia, edited by R. Jeffery \& A. M. Basu, pp. 150-183. New Delhi: Sage.

Jeffrey, Robin. 1993. Politics, Women and Well-Being: How Kerala Became "A Model." Delhi: Oxford University Press.

Kishor, Sunita. 1994. Fertility decline in Tamil Nadu, India. In: Understanding Reproductive Change: Kenya, Tamil Nadu, Punjab, Costa Rica, edited by Bertil Egerö and M. Hammarskjöld. Lund: Lund University Press.

Kravdal Øystein 2003. The problematic estimation of "imitation effects" in multilevel models. Demographic Research 9, article 2:25-40, in http://www.demographicresearch.org/volumes/vol9/2/, doi:10.4054/DemRes.2003.9.2.

Krishnamoorty, S., P. M. Kulkarni and N. Audinarayana. 2005. Causes of fertility transition in Tamil Nadu. In: Fertility Transition in South India, edited by Christophe Z. Guilmoto and S. Irudaya Rajan, pp. 227-247. New Delhi: Sage.

Lesthaeghe, R. 2010. The unfolding story of the second demographic transition. Population and Development Review 36(2):211-251.

McNay, K., P. Arokiasamy and R. H. Cassen. 2003. Why are uneducated women in India using contraception? A multilevel analysis. Population Studies 57(1): 21-40.

McNicoll, G. 2009. Legacy, Policy, and Circumstance in Fertility Transition. Population and Development Review 35(4):777-795.

Malhotra, A., R. Vanneman and S. Kishor. 1995. Fertility, patriarchy, and development in India. Population and Development Review 21(2):281-306.

Matthews, Zoë, Sabu S. Padmadas, Inge Hutter, Juliet McEachran and James J. Brown. 2009. Does early childbearing and a sterilization-focused family planning programme in India fuel population growth? Demographic Research 20, article 28, pp. 693-720. Available in http://www.demographic-research.org/Volumes/Vol20/28/

Morgan, S. P., S. Stash, H. L. Smith and K. O. Mason. 2002. Muslim and non-muslim differences in female autonomy and fertility: Evidence from four asian countries. Population and Development Review, 28(3): 515-537.

Moultrie T. A., V. Hosegood, N. McGrath, C. Hill and K. Herbst. 2008. Refining the criteria for stalled fertility declines: An application to rural KwaZulu-Natal, South Africa, 1990-2005. Studies in Family Planning 39(1):39-48.

Murthi, M., A. C. Guio and J. Drèze. 1995. Mortality, fertility and gender bias in India: A district level analysis. Population and Development Review 21: 745-782.

Myrskyla M., H. P. Kohler and F. C. Billari. 2009. Advances in development reverse fertility declines. Nature 460(7256):741-3.

Nauck, B. 2007. Value of children and the framing of fertility: Results from a cross-cultural comparative survey in 10 societies. European Sociological Review 23(5):615-629.

Padmadas S. S., I. Hutter and F. Willekens. 2004. Compression of women's reproductive spans in Andhra Pradesh, India. International Family Planning Perspectives 30(1):12-19.

Rahman, Lupin and Vijayendra Rao. 2004. The determinants of gender equity in India: Examining Dyson and Moore's thesis with new data. Population and Development Review 30(2):239-268. 
Ramachandran, P. and P. Ramesh. 2005. Fertility trends and differentials in Andhra Pradesh. In: Fertility Transition in South India, ed. by Christophe Z. Guilmoto and S. Irudaya Rajan, pp. 114-136. New Delhi: Sage.

Säävälä, Minna. 1999. Understanding the prevalence of female sterilization in rural South India. Studies in Family Planning 30(4):288-301.

--- 2001. Fertility and Familial Power Relations: Procreation in South India. Richmond: Curzon.

--ond 2006. Sterilized mothers: Women's personhood and family planning in rural South India. In: Culture, Power and Agency: Gender in Indian Ethnography, edited by Lina Fruzzetti and Sirpa Tenhunen. Kolkata: Stree.

Srinivasan, K. 1995. Regulating Reproduction in India's Population: Efforts, Results, and Recommendation. Sage Publications: New Delhi.

Srinivasan K. and Sanjay Kumar. 2005. Significance of medical and paramedical personnel in demographic transition: an empirical analysis. In: Fertility Transition in South India, edited by Christophe Z. Guilmoto and S. Irudaya Rajan, pp. 309-323. New Delhi: Sage.

United Nations. 2010. Population Division of the Department of Economic and Social Affairs of the United Nations Secretariat. World Population Prospects: The 2008 Revision, http://esa.un.org/unpp.

United Nations Development Fund (UNDP). 2009. Human Development Report 2009. Overcoming barriers: Human mobility and development. New York: Palgrave Macmillan.

U S Census Bureau 2010. International Data Base. In http://sasweb.ssd.census.gov/ idb/ranks.html.

Véron, J. 2008. The demography of South Asia from the 1950s to the 2000s. A summary of changes and statistical assessment. Population (English edition) 63(1):9-89.

Vlassoff, C. 1996. Against the odds: The changing impact of schooling on female autonomy and fertility in an Indian village. In: Girls 'Schooling, Women's Autonomy and Fertility Change in South Asia edited by Jeffery R. and A. M. Basu, pp. 218-234. New Delhi: Sage. 